\title{
The influence of environmental parameters on the thermographic analysis of the building envelope
}

\author{
by S. Van De Vijver ${ }^{*}$, M. Steeman ${ }^{*}$, N. Van Den Bossche*, K. Carbonez ${ }^{*}$, A. Janssens ${ }^{*}$ \\ *Ghent University, 9000 Ghent, Belgium, Sven.VanDeVijver@Ugent.be
}

\begin{abstract}
Typically, thermographic measurements are used to analyze the building envelope in a qualitative way (e.g. detection of thermal bridges, missing insulation, etc.). Besides, thermography can also be used to obtain surface temperatures, which can give an indication of the thermal performance of the building envelope. In this paper the influence of the most important environmental parameters on the thermographic analysis of different wall types is examined using a multivariable parameter study. This results in guidelines that are in good accordance with the existing guidelines. Furthermore some remarks were made concerning the ambiguities in the existing guidelines.
\end{abstract}

\section{INTRODUCTION}

Europe has high ambitions concerning energy efficiency and the reduction of greenhouse gas emissions. By 2050 , one of the goals is to reduce the $\mathrm{CO}_{2}$-emissions by more than $80 \%$, which is impossible with the current policy. In order to reach this goal, the percentage of renovated buildings has to increase from $1 \%$ to around $2,5 \%$ per year by 2020 [1]. For new buildings, one of the key factors to satisfy the need for energy efficiency is a high performing building envelope, which can be achieved by a high insulation level and an excellent airtightness. In this context, infrared thermography (IR) is a valuable non-destructive tool which can be used both for evaluating the execution quality of the building envelope or for determining where renovation of the building envelope is necessary. For a proper assessment of the wall surface temperature the building envelope has to be as close as possible to steady-state conditions. Therefore an adequate knowledge of the influence of environmental parameters (solar irradiation, wind velocity, sky radiation, etc.) and building parameters (thermal mass of the structure) on the dynamic behavior of the building envelope is needed. Due to the large number of parameters that influence this dynamic behavior together with the limitations of the existing thermographic cameras, additional research is necessary to make quantitative surveys more reliable. In what follows an overview of the currently existing guidelines is given. Starting from the existing guidelines, simulations were conducted to investigate the dynamic behaviour of the wall surface temperature for different combinations of environmental parameters. Finally, feedback on the currently existing standards is given taking into account the results obtained by the simulations.

\section{EXISTING GUIDELINES FOR EXTERNAL THERMOGRAPHIC EVALUATION}

Extensive research has already been performed on the influence of the different environmental parameters on the dynamic behaviour of the building envelope, resulting in numerous guidelines. Unfortunately the guidelines found in standards (among each other) and in scientific literature do not agree. On the contrary, the existing guidelines are rather vague and even sometimes contradicting and on top of that seldom a distinction is made between different wall structures (important for thermal mass) or different types of thermographic surveys such as evaluation of insulation defects, air leakages or quantitative inspections. In table 1 an overview of the currently existing guidelines is shown taking into account the construction type and the type of survey (for wind velocity and inside-outside temperature difference). This overview includes both standards and guidelines originating from scientific literature.

Table 1. Overview of the influencing environmental parameters and their limitations

\begin{tabular}{|c|c|c|c|}
\hline Construction type & Light & Medium & Heavy \\
\hline \multirow{6}{*}{ Solar irradiation } & $\begin{array}{c}\text { No solar irradiation } \\
\text { allowed during } 3 \mathrm{~h} \text { prior to } \\
\text { investigation [2] }\end{array}$ & $\begin{array}{l}\text { No solar irradiation allowed } \\
\text { during 8h prior to } \\
\text { investigation [2] }\end{array}$ & \\
\hline & $\begin{array}{c}\text { IR possible several } \mathrm{h} \text { after } \\
\text { exposure }[3,4]\end{array}$ & $\begin{array}{c}\text { IR possible } 24 \mathrm{~h} \text { after } \\
\text { exposure }[3,4]\end{array}$ & $\begin{array}{c}\text { IR possible } 48 \mathrm{~h} \text { after } \\
\text { exposure }[3,4]\end{array}$ \\
\hline & $\begin{array}{c}\text { IR possible } 2-3 \mathrm{~h} \text { after } \\
\text { exposure [5] }\end{array}$ & $\begin{array}{l}\text { IR possible } 4-6 \mathrm{~h} \text { after } \\
\text { exposure [5] }\end{array}$ & $\begin{array}{c}\text { IR possible } 8 \mathrm{~h} \text { after } \\
\text { exposure [5] }\end{array}$ \\
\hline & \multicolumn{3}{|c|}{ Not allowed $12 \mathrm{~h}$ prior to IR $[6,7,8]$} \\
\hline & \multicolumn{3}{|c|}{ Structures with high thermal mass need more attention $[6,7]$} \\
\hline & \multicolumn{3}{|c|}{ Not allowed $[9,10,11,12,13,14,15]$} \\
\hline
\end{tabular}




\begin{tabular}{|c|c|c|c|}
\hline \multirow{5}{*}{$\begin{array}{l}\text { Temperature } \\
\text { gradient }\end{array}$} & $\Delta \mathrm{T}_{\mathrm{s}}=0,5^{*} \Delta \mathrm{T}_{\mathrm{e}, \mathrm{grad}}[3,4]$ & $\Delta \mathrm{T}_{\mathrm{s}}=0,35^{*} \Delta \mathrm{T}_{\mathrm{e}, \mathrm{grad}}[3,4]$ & $\Delta \mathrm{T}_{\mathrm{s}}=0,2{ }^{*} \Delta \mathrm{T}_{\mathrm{e}, \mathrm{grad}}[3,4]$ \\
\hline & \multicolumn{3}{|c|}{$\Delta \mathrm{T}$, grad low and stable during IR [10] } \\
\hline & \multicolumn{3}{|c|}{$\Delta \mathrm{T}_{\mathrm{e}, \mathrm{grad}}<10^{\circ} \mathrm{C} 24 \mathrm{~h}$ prior to $\mathrm{IR},<5^{\circ} \mathrm{C}$ during $\mathrm{IR}[6,7,12]$} \\
\hline & \multicolumn{3}{|c|}{$\Delta \mathrm{T}_{\mathrm{i}, \mathrm{grad}}<2^{\circ} \mathrm{C}$ during IR $[6,7,16]$} \\
\hline & \multicolumn{3}{|c|}{$\Delta \mathrm{T}_{\mathrm{e}, \text { grad }}<5^{\circ} \mathrm{C}$ during $\mathrm{IR}[6,7,16]$} \\
\hline \multirow{5}{*}{ Precipitation } & \multicolumn{3}{|c|}{ To avoid $[10,14]$} \\
\hline & \multicolumn{3}{|c|}{ No influence on IR from small distance $[3,17]$} \\
\hline & \multicolumn{3}{|c|}{ Wet surface or with snow covered surface not allowed $[2,3,17]$} \\
\hline & \multicolumn{3}{|c|}{ Makes it impossible to do an IR [15] } \\
\hline & \multicolumn{3}{|c|}{ For roof inspection the roof surface has to be dry $[9,10,18]$} \\
\hline \multirow{3}{*}{ Sky radiation } & \multicolumn{3}{|c|}{ Ideal when fully overcast sky $[9,14,17]$} \\
\hline & \multirow{2}{*}{\multicolumn{3}{|c|}{$\begin{array}{c}\text { Covered surface }=\mathrm{T}_{\text {obj }} \approx \mathrm{T}_{\text {omg }}=\text { ideal circumstances }[4,11] \\
\text { Important influence on } T_{\text {ref }}[19]\end{array}$}} \\
\hline & & & \\
\hline \multirow{11}{*}{$\begin{array}{c}\text { Temperature } \\
\text { difference } \\
\text { inside/outside } \\
\left(\Delta \mathbf{T}_{\mathrm{i}-\mathrm{e}}\right)\end{array}$} & Insulation defects & & eakage spots \\
\hline & $\Delta \mathrm{T}_{\mathrm{i}-\mathrm{e}}>10^{\circ} \mathrm{C}$ during $4 \mathrm{~h}$ prior to IR [20] & $\Delta \mathrm{T}_{\mathrm{i}-\mathrm{e}}>1,7^{\circ}$ & luring $4 \mathrm{~h}$ prior to IR [20] \\
\hline & $\Delta \mathrm{T}_{\mathrm{i}-\mathrm{e}}>10^{\circ} \mathrm{C}[10]$ & & i-e $>3^{\circ} \mathrm{C}[10]$ \\
\hline & $\Delta \mathrm{T}_{\mathrm{i}-\mathrm{e}}>10^{\circ} \mathrm{C}[21]$ & & i-e $>5^{\circ} \mathrm{C}[21]$ \\
\hline & \multicolumn{3}{|c|}{$\Delta \mathrm{T}_{\mathrm{i}-\mathrm{e}}>10^{\circ} \mathrm{C}[11]$} \\
\hline & \multicolumn{3}{|c|}{$\Delta \mathrm{T}_{\mathrm{i}-\mathrm{e}}>3 / \mathrm{U}\left(\min 5^{\circ} \mathrm{C}\right)$ during $24 \mathrm{~h}$ prior to IR $[8,16]$} \\
\hline & \multicolumn{3}{|c|}{$\Delta \mathrm{T}_{\mathrm{i}-\mathrm{e}}>15^{\circ} \mathrm{C}$ during $24 \mathrm{~h}$ prior to IR $[15,22]$} \\
\hline & \multicolumn{3}{|c|}{$\Delta \mathrm{T}_{\mathrm{i}-\mathrm{e}}>10-15^{\circ} \mathrm{C}[13,23]$} \\
\hline & \multicolumn{3}{|c|}{$\Delta \mathrm{T}_{\mathrm{i}-\mathrm{e}}>5^{\circ} \mathrm{C}$ during $24 \mathrm{~h}$ prior to IR $[6,7,12]$} \\
\hline & \multicolumn{3}{|c|}{$\Delta \mathrm{T}_{\mathrm{i}-\mathrm{e}}>10^{\circ} \mathrm{C}$ during $4 \mathrm{~h}$ prior to IR $[2,24]$} \\
\hline & \multicolumn{3}{|c|}{$\Delta \mathrm{T}_{\mathrm{i}-\mathrm{e}}>10^{\circ} \mathrm{C}\left(>20^{\circ} \mathrm{C}\right.$ if possible for U-value determination) [19] } \\
\hline \multirow{6}{*}{ Wind velocity $(\mathrm{m} / \mathrm{s})$} & Qualitative inspection & & tative inspection \\
\hline & $2,7 \mathrm{~m} / \mathrm{s}[13]$ & & ial 0,2$) \mathrm{m} / \mathrm{s}[13]$ \\
\hline & \multicolumn{3}{|c|}{$5 \mathrm{~m} / \mathrm{s}[9,21]$} \\
\hline & \multicolumn{3}{|c|}{$6,7 \mathrm{~m} / \mathrm{s}[2,10]$} \\
\hline & \multicolumn{3}{|c|}{$3,6 \mathrm{~m} / \mathrm{s}[20]$} \\
\hline & \multicolumn{3}{|c|}{$2 \mathrm{~m} / \mathrm{s}[3,4,14,15]$} \\
\hline
\end{tabular}

Looking at the guidelines for solar irradiation for instance, three groups of authors can be distinguished. A first group of authors $[9,10,11,12,13,14,15]$ recommends to avoid solar irradiation in general, making no judgement of the impact duration. A second group [6, 7, 8 ], containing also the European Standards on thermography, gives more precise information on the waiting time after sundown to perform a thermographic survey and mentions that structures with high thermal mass need more attention. A third group [2, 3, 4, 5] of authors distinguishes between guidelines for structures with a different thermal mass. A large difference can be noticed between the European guidelines $[3,4]$ and these from the USA [2,5]. This is probably due to the different building practices (masonry versus timber). In [4] the influence of the environmental parameters is investigated using Voltra, a 3-dimensional dynamic simulation tool using the finite element method [25]. Figure 1 shows the influence of the absorbed solar energy on the time decay between sundown and the moment where a thermographic investigation can be performed.

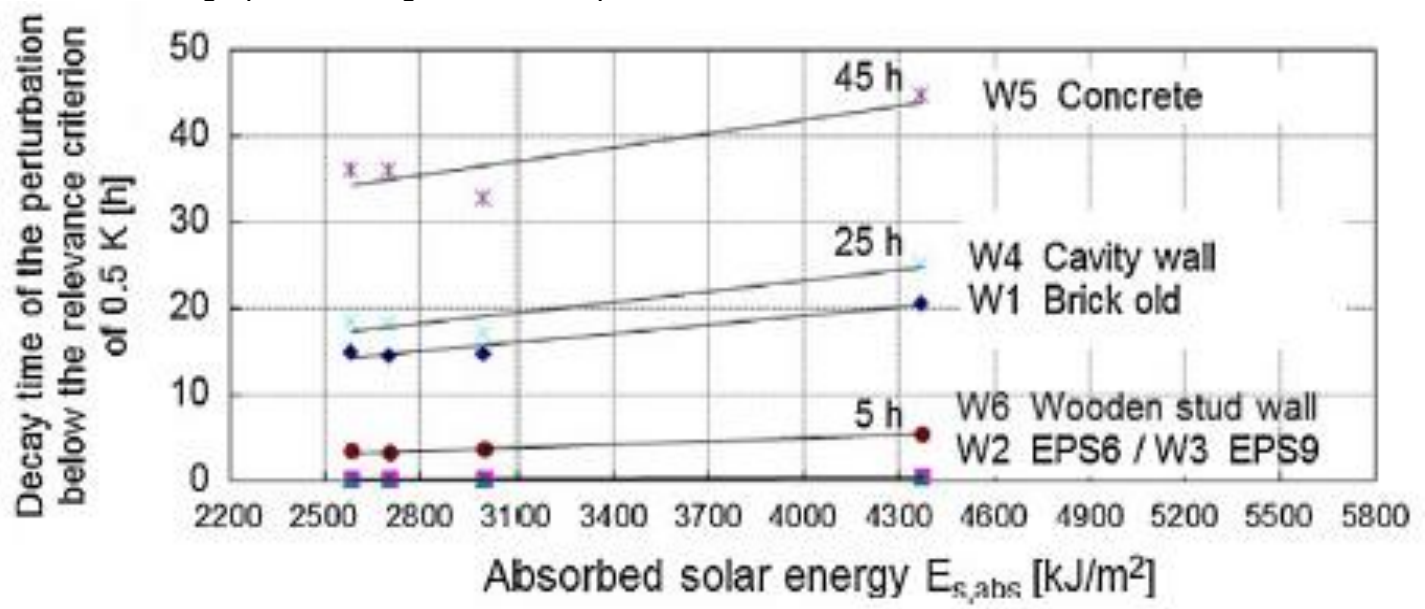

Fig. 1. The impact time of solar irradiation on different types of structures [4]

Considering the wind velocity, which has a direct influence on the convective heat transfer coefficient, a large difference between the specified maximum values can be noticed ranging from $1 \mathrm{~m} / \mathrm{s}$ to $6,7 \mathrm{~m} / \mathrm{s}$. In Belgium, where the 
mean annual wind velocity is about $3,5 \mathrm{~m} / \mathrm{s}$ [26], the maximum values proposed by [2, 9, 10, 21] will be met during the major part of the year. The values proposed for quantitative measurements on the contrary are hardly ever met [13].

For the temperature difference between the inside and the outside, a distinction is made between an evaluation of insulation defects and surveys to reveal air leakage spots. Especially the guidelines for surveys to reveal air leakage spots do not agree about the minimum temperature difference, giving minimum temperature differences between the inside and outside ranging from $1,7^{\circ} \mathrm{C}$ to $5^{\circ} \mathrm{C}[10,20,21]$.

\section{SIMULATIONS AND RESULTING GUIDELINES}

\subsection{Simulation model}

In this paper the simulations were conducted in Voltra. This simulation program has proven to be in good accordance with in situ measurement results in previous studies [4]. A selection of six wall types, commonly found in Flanders, was modelled in Voltra. As can be seen in figure 2 the investigated wall types are the partly filled cavity wall (a), the fully filled cavity wall (b), the non-insulated cavity wall (c), the massive wall with outside (d) and inside (e) insulation and the timber frame wall (f). It was ensured that all the insulated wall types had a U-value of approximately $0,23 \mathrm{~W} / \mathrm{m}^{2} \mathrm{~K}$, which is in accordance with the current EPBD-regulations. For the non-insulated cavity wall an U-value of about $1 \mathrm{~W} / \mathrm{m}^{2} \mathrm{~K}$ was considered.

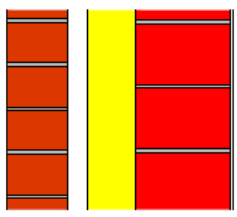

(a)

\begin{tabular}{l|c} 
Wall construction & $\begin{array}{c}90 \mathrm{~mm} \text { masonry }-40 \\
\text { air cavity }-120 \mathrm{~mm} \\
\text { insulation }-190 \mathrm{~m} \\
\text { masonry }-20 \mathrm{~mm} \text { gy }\end{array}$ \\
\hline Thermal effusivity $\left(\mathrm{J} / \mathrm{m}^{2} \mathrm{~K} \sqrt{\mathrm{s}}\right)$ & 531,21 \\
\hline Penetration depth $(\mathrm{m})$ & 0,10 \\
\hline Heat capacity $(\mathrm{kJ} / \mathrm{K})$ & 88,1 \\
& $\mid$\begin{tabular}{c|c}
$\ldots$ \\
$\cdots$
\end{tabular}
\end{tabular}

(d)

Wall construction

\begin{tabular}{l|c} 
& $\begin{array}{c}0,035 \text { insulation }-190 \mathrm{~mm} \\
\text { reinforced concrete - } \\
\text { 20mm gypsum }\end{array}$ \\
\hline Thermal effusivity $\left(\mathrm{J} / \mathrm{m}^{2} \mathrm{~K} \sqrt{\mathrm{s}}\right)$ & 32,40 \\
\hline Penetration depth $(\mathrm{m})$ & 0,18 \\
\hline Heat capacity $(\mathrm{kJ} / \mathrm{K})$ & 5,4
\end{tabular}

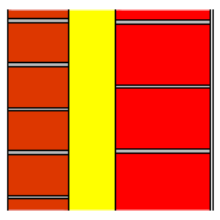

(b)

90mm masonry - 120mm

0,035 insulation -

$190 \mathrm{~mm}$ masonry - $20 \mathrm{~mm}$ gypsum

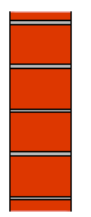

(c)

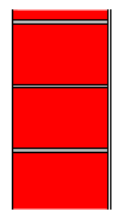

) air cavity $-190 \mathrm{~mm}$ masonry - $20 \mathrm{~mm}$ gypsum

$531,21 \quad 531,21$

$\begin{array}{ll}0,10 & 0,10 \\ 88,1 & 88,1\end{array}$

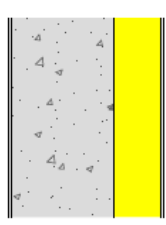

(e)

reinforcedconcrete $142 \mathrm{~mm} 0,035$ insulation $-20 \mathrm{~mm}$ gypsum

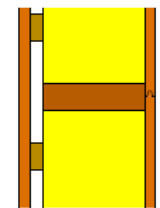

(f)

$25 \mathrm{~mm}$ OSB - $135 \mathrm{~mm}$

0,035 insulation $-25 \mathrm{~mm}$ OSB

Fig. 2. Different wall types were modelled in Voltra

\subsection{Multivariable analysis}

In a previous research project a one-at-a-time parameter study was conducted to check the influence of each environmental parameter separately [4]. In reality however, the effect on the wall surface temperature is a combined effect of e.g. the wind velocity, the solar irradiation and the sky radiation. For example, it can be expected that a high wind velocity leading to a high surface cooling will partly attenuate the effect of solar radiation on the building envelope. Therefore a multivariable analysis was performed combining all different values of the wind velocity, the sky radiation and the solar radiation (200 simulations).

The simulations were conducted using the weather data from a test reference year of Uccle (Belgium) [26]. A simulation period of 7 days (and a startup period of 3 days) starting the $1^{\text {th }}$ of February was chosen. In this case the weather data of the fourth day of the simulation period (February $4^{\text {th }}$ ) were adjusted (Fig. 3). In table 2 an overview of the parameter values used for the base case and their range are shown. 
Table 2: Range of the investigated parameter values and base case

\begin{tabular}{|c|c|c|c|c|c|c|}
\hline & $\begin{array}{l}\text { Wind } \\
\text { velocity }\end{array}$ & $\mathbf{h}_{\mathbf{c}}^{*}$ & $\begin{array}{c}\text { Solar } \\
\text { irradiation }\end{array}$ & $\begin{array}{l}\text { Temperature } \\
\text { difference between } \\
\text { the radiation } \\
\text { temperature of the } \\
\text { sky and the air } \\
\text { temperature }\end{array}$ & Orientation & $\begin{array}{c}\text { Outdoor } \\
\text { temperature gradiënt }\end{array}$ \\
\hline \multirow[t]{8}{*}{ Base case } & $0 \mathrm{~m} / \mathrm{s}$ & $1,8 \mathrm{~W} / \mathrm{m}^{2} \mathrm{~K}$ & 01 & $\Delta T_{\text {sky-air }}=2,5^{\circ} \mathrm{C}$ & South & TRY Uccle \\
\hline & $1 \mathrm{~m} / \mathrm{s}$ & $5,9 \mathrm{~W} / \mathrm{m}^{2} \mathrm{~K}$ & 0,251 & $\Delta \mathrm{T}_{\text {sky-air }}=5{ }^{\circ} \mathrm{C}$ & West & $0^{\circ} \mathrm{C} / \mathrm{h}$ \\
\hline & $2 \mathrm{~m} / \mathrm{s}$ & $8,4 \mathrm{~W} / \mathrm{m}^{2} \mathrm{~K}$ & 0,501 & $\Delta \mathrm{T}_{\text {sky-air }}=10^{\circ} \mathrm{C}$ & North & $1^{\circ} \mathrm{C} / \mathrm{h}$ \\
\hline & $3 \mathrm{~m} / \mathrm{s}$ & $10,4 \mathrm{~W} / \mathrm{m}^{2} \mathrm{~K}$ & 0,75 I & $\Delta \mathrm{T}_{\text {sky-air }}=15^{\circ} \mathrm{C}$ & East & $2{ }^{\circ} \mathrm{C} / \mathrm{h}$ \\
\hline & $4 \mathrm{~m} / \mathrm{s}$ & $12,0 \mathrm{~W} / \mathrm{m}^{2} \mathrm{~K}$ & 11 & $\Delta \mathrm{T}_{\text {sky-air }}=20^{\circ} \mathrm{C}$ & & $3^{\circ} \mathrm{C} / \mathrm{h}$ \\
\hline & $5 \mathrm{~m} / \mathrm{s}$ & $13,5 \mathrm{~W} / \mathrm{m}^{2} \mathrm{~K}$ & & & & $4{ }^{\circ} \mathrm{C} / \mathrm{h}$ \\
\hline & $6 \mathrm{~m} / \mathrm{s}$ & $14,9 \mathrm{~W} / \mathrm{m}^{2} \mathrm{~K}$ & & & & $5{ }^{\circ} \mathrm{C} / \mathrm{h}$ \\
\hline & $7 \mathrm{~m} / \mathrm{s}$ & $16,1 \mathrm{~W} / \mathrm{m}^{2} \mathrm{~K}$ & & & & $10^{\circ} \mathrm{C} / \mathrm{h}$ \\
\hline
\end{tabular}

$\left.{ }^{*}\right)$ according to correlation used by Taki and Loveday $\left(\mathrm{h}_{\mathrm{c}}=\mathrm{f}\left(\mathrm{v}_{\text {wind }}\right)\right.$

If the wall surface temperature in the base case $\left(T_{s, r e f}\right)$ is then subtracted from the wall surface temperature of the weather file with combined parameter values $\left(T_{s, x}\right)$, a temperature difference is obtained $\left(\Delta T_{s}\right)(E q .1)$.

$$
\Delta T s=T x, s-T s, r e f
$$

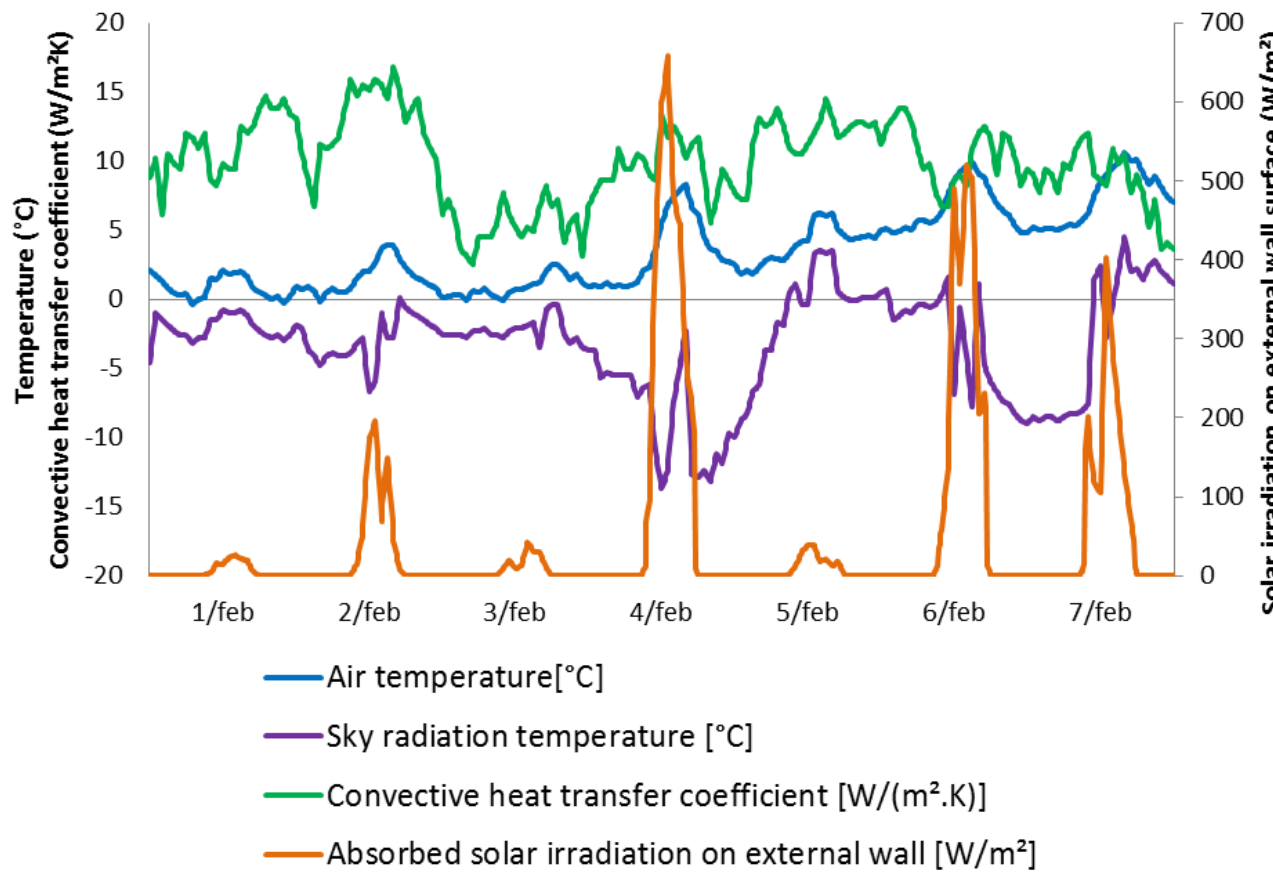

Fig. 3. Weather data of the climatic file for the simulation period

For each simulation, the temperature difference $\Delta T_{s}$ between the studied case and the base case just after sundown of day four of the simulation was evaluated. This is the moment that the modified parameters (e.g. wind velocity, solar radiation...) are restored to the reference values. After a period of time, depending on the wall type and the studied case, the temperature difference becomes smaller than a predetermined value. A value of $0,5^{\circ} \mathrm{C}-$ which is considered as the accuracy of the camera after extensive calibration in laboratory [27] - and $2^{\circ} \mathrm{C}-$ which is the accuracy of current thermographic cameras - were considered for quantitative and qualitative measurements respectively. The time between sundown and the moment that the temperature drops under one of these values, is equal to the time a thermographer has to wait after sundown to perform a reliable thermographic survey. Eq. 2 expresses this waiting period (decay time $\left.t_{\text {dec }}\right)$ :

$$
\begin{aligned}
& \text { Quantitative: } t_{\mathrm{dec}}=t(\Delta T s<0,5) \\
& \text { Qualitative: } t_{\mathrm{dec}}=t(\Delta T s<2,0)
\end{aligned}
$$




\subsection{Simulation results}

In this part an overview of the most important simulation results is given. A general overview of the spread of the simulation results is shown in Fig.4. This graph shows the waiting time before starting a thermographic survey after a specific phenomenon on the x-axis and the maximal temperature difference during the phenomenon with respect to the base case on the $y$-axis. Three different types of walls can be clearly identified: walls with light thermal mass, medium thermal mass and heavy thermal mass.

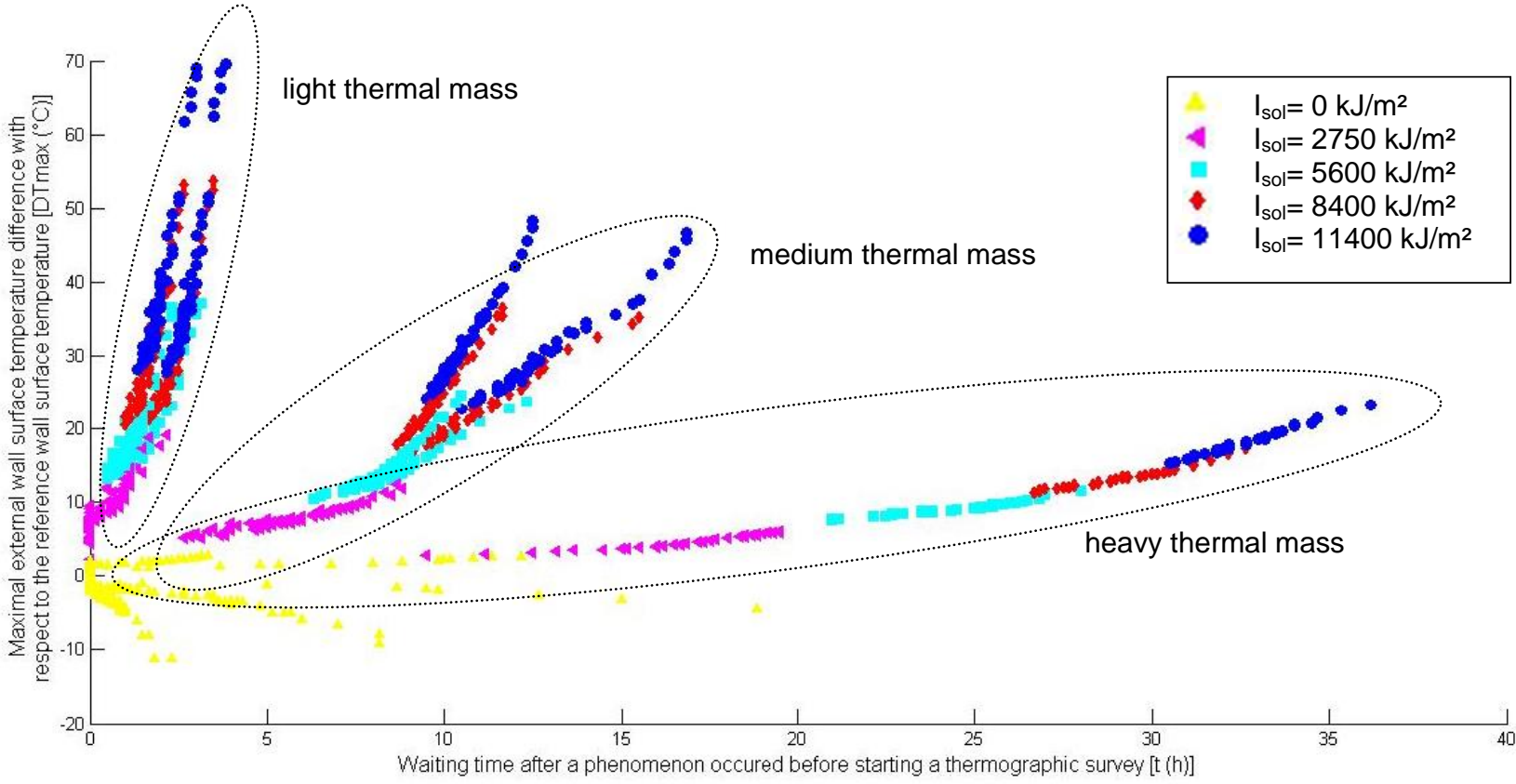

Fig. 4: Results of the maximal external wall surface temperature and the waiting time for the multivariable parameter study

\subsubsection{Solar irradiation}

In Figure 4 the influence of the absorbed solar irradiation on the waiting time before performing a thermographic survey is depicted. In table 3 the waiting time for each value of absorbed solar irradiation for each wall type is given. For wall types with light thermal mass the waiting period for quantitative IR measurements (threshold value of $0.5^{\circ} \mathrm{C}$ ) lies in the range of 0 to 4 hours, for wall types with medium thermal mass within 0 to 17 hours and for wall types with heavy thermal mass within 0 to 36 hours. The waiting times for qualitative IR measurements (threshold value of $2{ }^{\circ} \mathrm{C}$ ) can be found in Table 4.

Table 3: The waiting time before performing a thermographic survey for a threshold value of $0,5^{\circ} \mathrm{C}$

\begin{tabular}{|c|c|c|c|c|c|c|}
\hline $\begin{array}{c}\text { Threshold value }= \\
0,5^{\circ} \mathrm{C}\end{array}$ & $\begin{array}{l}\text { Timber } \\
\text { frame } \\
\text { wall }\end{array}$ & $\begin{array}{l}\text { Massive wall } \\
\text { with inside } \\
\text { insulation }\end{array}$ & $\begin{array}{l}\text { Massive wall } \\
\text { with outside } \\
\text { insulation }\end{array}$ & $\begin{array}{l}\text { Fully filled } \\
\text { cavity wall }\end{array}$ & $\begin{array}{l}\text { Non-insulated } \\
\text { cavity wall }\end{array}$ & $\begin{array}{l}\text { Partly filled } \\
\text { cavity wall }\end{array}$ \\
\hline $1,0 \mathrm{l}\left(11400 \mathrm{~kJ} / \mathrm{m}^{2}\right)$ & $2-4 h$ & $31-36 h$ & $1,5-3 h$ & $9,5-13 h$ & $11-17 \mathrm{~h}$ & $9,5-13 h$ \\
\hline $0,75 \mathrm{I}\left(8400 \mathrm{~kJ} / \mathrm{m}^{2}\right)$ & $1,5-3,5 h$ & $26-33 h$ & $1-2,75 h$ & $9-12 h$ & $9-15,5 h$ & $9-12 h$ \\
\hline $0,50 \mathrm{I}\left(5600 \mathrm{~kJ} / \mathrm{m}^{2}\right)$ & $0,5-3 h$ & $20-27 h$ & $0,5-2,5 h$ & $7-11 \mathrm{~h}$ & $6-12,5 h$ & $7-11 h$ \\
\hline $0,25 \mathrm{I}\left(2750 \mathrm{~kJ} / \mathrm{m}^{2}\right)$ & $0-2,5 h$ & $0-20 h$ & $0-1,5 \mathrm{~h}$ & $3-9 h$ & $0-9 h$ & $3-9 h$ \\
\hline $0,0 \mathrm{I}\left(0 \mathrm{~kJ} / \mathrm{m}^{2}\right)$ & $0-2,5 \mathrm{~h}$ & $0-20 \mathrm{~h}$ & $0-2 h$ & $0-8 h$ & $0-8 h$ & $0-8 h$ \\
\hline
\end{tabular}

Table 4: The waiting time before performing a thermographic survey for a threshold value of 2,0 ${ }^{\circ} \mathrm{C}$

\begin{tabular}{|c|c|c|c|c|c|c|}
\hline $\begin{array}{l}\text { Threshold value }= \\
\qquad 2^{\circ} \mathrm{C}\end{array}$ & $\begin{array}{c}\text { Timber } \\
\text { frame } \\
\text { wall }\end{array}$ & $\begin{array}{l}\text { Massive wall } \\
\text { with inside } \\
\text { insulation }\end{array}$ & $\begin{array}{l}\text { Massive wall } \\
\text { with outside } \\
\text { insulation }\end{array}$ & $\begin{array}{l}\text { Fully filled } \\
\text { cavity wall }\end{array}$ & $\begin{array}{l}\text { Non-insulated } \\
\text { cavity wall }\end{array}$ & $\begin{array}{l}\text { Partly filled } \\
\text { cavity wall }\end{array}$ \\
\hline $1,0 \mathrm{I}\left(11400 \mathrm{~kJ} / \mathrm{m}^{2}\right)$ & $0-1,5 \mathrm{~h}$ & $10-17 \mathrm{~h}$ & $0-1,2 \mathrm{~h}$ & $3,5-7 h$ & $2-6,5 h$ & $3,5-7 h$ \\
\hline $0,75 \mathrm{I}\left(8400 \mathrm{~kJ} / \mathrm{m}^{2}\right)$ & $0-1 \mathrm{~h}$ & $8-13 h$ & $0-1 \mathrm{~h}$ & $2-6 h$ & $0,2-5 h$ & $2-6 h$ \\
\hline $0,50 \mathrm{I}\left(5600 \mathrm{~kJ} / \mathrm{m}^{2}\right)$ & Oh & $2,5-9 h$ & $0-0,7 \mathrm{~h}$ & $0-4,5 h$ & $0-3,5 h$ & $0-4,5 h$ \\
\hline $0,25 \mathrm{I}\left(2750 \mathrm{~kJ} / \mathrm{m}^{2}\right)$ & $\mathrm{Oh}$ & $0-1 \mathrm{~h}$ & $0-0,2 \mathrm{~h}$ & $0-2 h$ & $0-0,5 h$ & $0-2 h$ \\
\hline $0,0 \mathrm{I}\left(0 \mathrm{~kJ} / \mathrm{m}^{2}\right)$ & $0-0,2 h$ & $0-0,2 h$ & $0-0,4 h$ & $0-1 \mathrm{~h}$ & $0-0,2 h$ & $0-1 \mathrm{~h}$ \\
\hline
\end{tabular}




\subsubsection{Wind velocity and sky radiation}

Looking at the influence of the wind velocity and the sky radiation, it is interesting to investigate what would be the wind speed for which a quantitative $\left(0,5^{\circ} \mathrm{C}\right.$, red dotted line) or a qualitative $\left(2^{\circ} \mathrm{C}\right.$, blue dotted line $)$ thermographic survey can still be performed during a windy day. Figure 5 shows the course of the temperature difference ( $y$-axis) between the base case and the cases with combined parameters of wind velocity, sky radiation and solar radiation from sunset to sundown (x-axis) for a timber frame wall.

In Fig 5 (top), all possible combinations of the wind velocity, solar irradiation and sky irradiation are included. This graph shows that qualitative nor quantitative thermographic evaluation is recommended during the majority of these outside conditions. Excluding the combinations with solar irradiation and clear sky $\left(\Delta \mathrm{T}_{\text {sky-air }}>5^{\circ} \mathrm{C}\right)$ shows that qualitative thermographic surveying is possible for wind velocities from $1 \mathrm{~m} / \mathrm{s}$ up to $7 \mathrm{~m} / \mathrm{s}$ since the temperature difference during the phenomenon remains under the threshold value of $2^{\circ} \mathrm{C}$ (Fig 5 bottom). Very little combinations also give reliable results for quantitative thermographic measurements: only the temperature difference profiles with a wind velocity lower than $1 \mathrm{~m} / \mathrm{s}$ in absence of solar radiation and with overcast sky, remain under the threshold value of $0,5^{\circ} \mathrm{C}$. In general solar irradiation and a clear sky should always be avoided. In the investigated case the wind velocity remains the same for 9 hours (from sunset to sundown), figure 5 shows however (dotted lines) that wind gusts lasting less than an hour do not have a significant influence for qualitative measurements. For this reason long lasting winds should also be avoided.

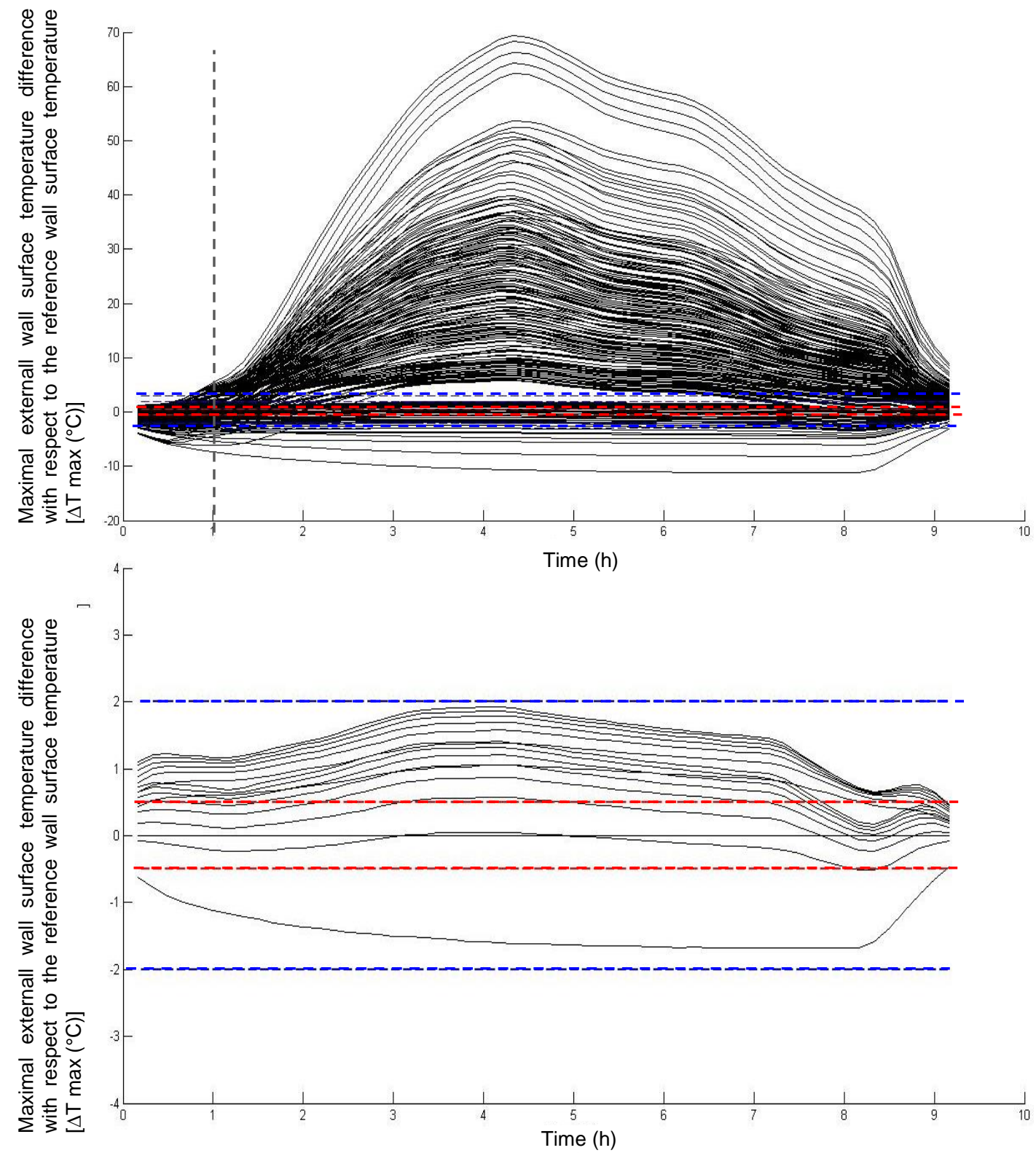

Fig. 5: Influence of sky radiation and wind velocity on the wall surface temperature difference for a timber frame wall: temperature difference curves for all possible combinations of wind velocity, solar irradiation and the sky radiation (top), and temperature difference curves for different values of the wind velocity in combination with an overcast sky and no solar irradiation (bottom) 


\subsubsection{Orientation}

The influence of the outdoor temperature gradient and the orientation of the wall are estimated separately, since their influence can be evaluated relative to respectively the southern orientation and a temperature gradient of zero. In Figure 6 the waiting time after sundown is shown for different orientations comparing the original weather file of Uccle with the base case (table 2). How lower the thermal mass, how smaller the influence of the orientation on the waiting time. For wall types with a low thermal mass (e.g. timber frame wall and massive wall with outside insulation), thermographic measurements on the wall surfaces facing north and east can be performed immediately after sundown. Due to the influence of diffuse solar irradiation, measurements before sunset are not recommended.

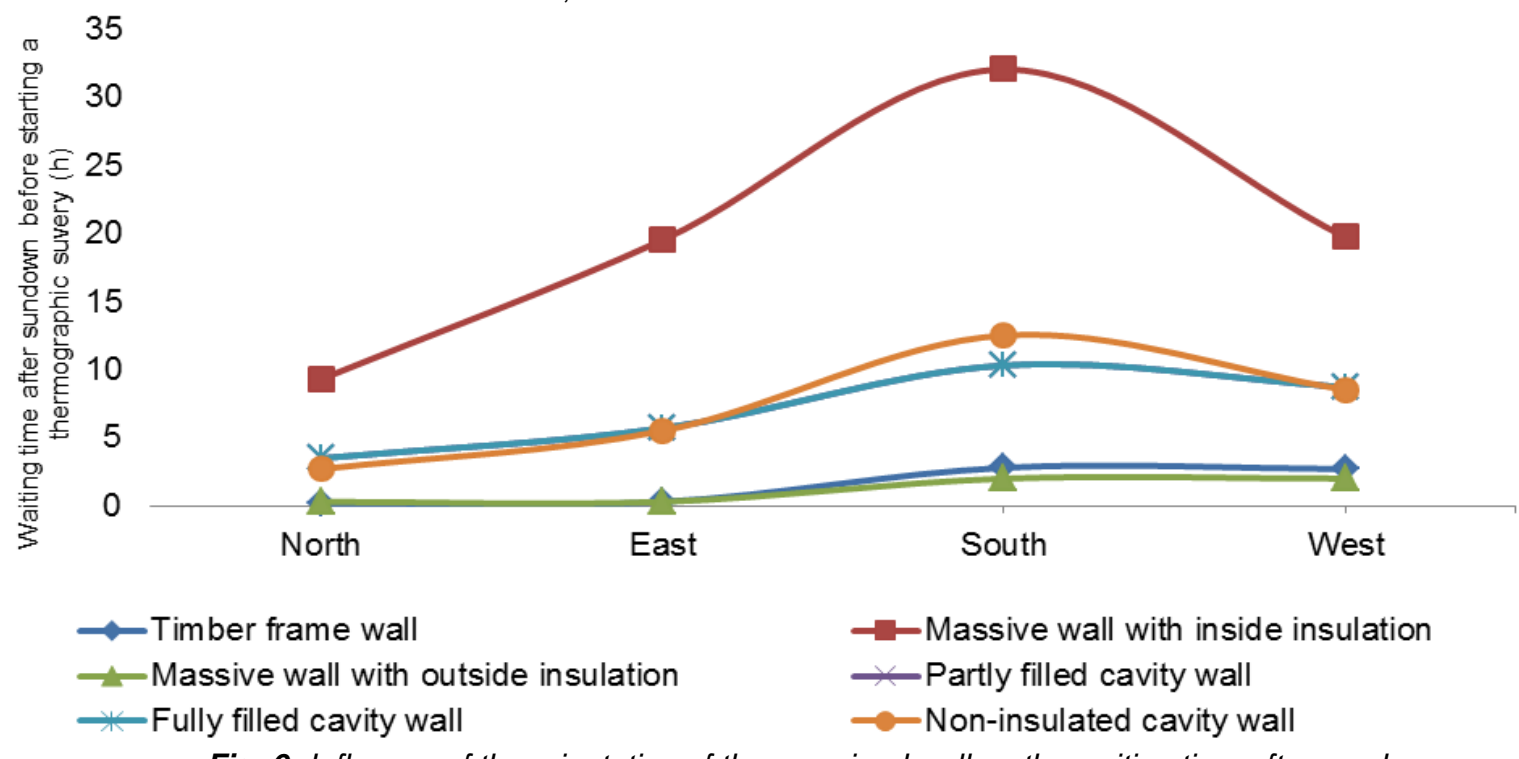

Fig. 6: Influence of the orientation of the examined wall on the waiting time after sundown

\subsubsection{Outside temperature gradient}

The temperature gradient of the outside air has an influence on the cooling rate (negative gradient) or warming up (positive gradient) of the wall. To estimate this rate for the different wall types, simulations with different temperature gradients ranging from $0{ }^{\circ} \mathrm{C} / \mathrm{h}$ (reference value) to $10{ }^{\circ} \mathrm{C} / \mathrm{h}$ were performed. For these specific simulations the other parameters like wind velocity, solar irradiation and sky radiation maintain their original values of the climatic file of Uccle. In Figure 7 the temperature courses for the different situations are given for the timber frame wall (a) and the massive wall with inside insulation (b). For the timber frame wall, for example, the cooling rate of the wall is equal to about $50 \%$ of the imposed outside temperature gradient (Fig. 7a). For the massive wall with inside insulation the cooling rate of the wall is equal to $25 \%$ of the imposed outside temperature gradient and on top of that, the influence of the temperature gradient remains visible for certain hours (Fig. 7b).

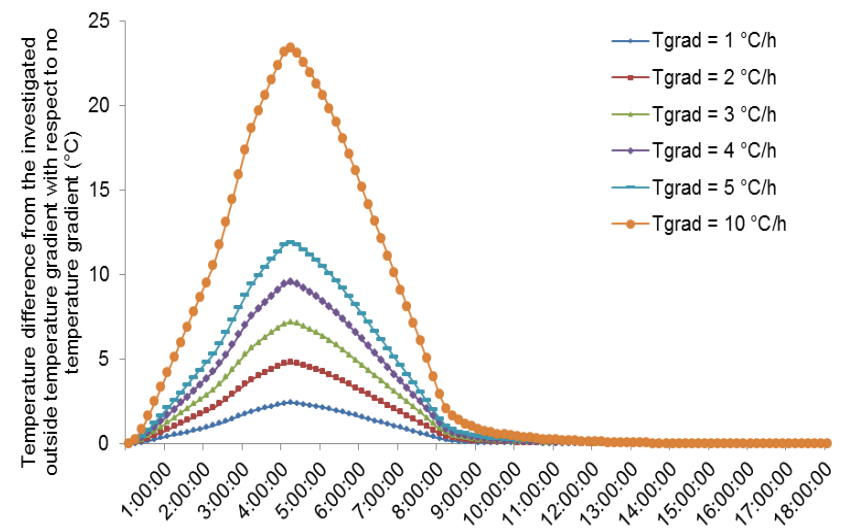

(a)

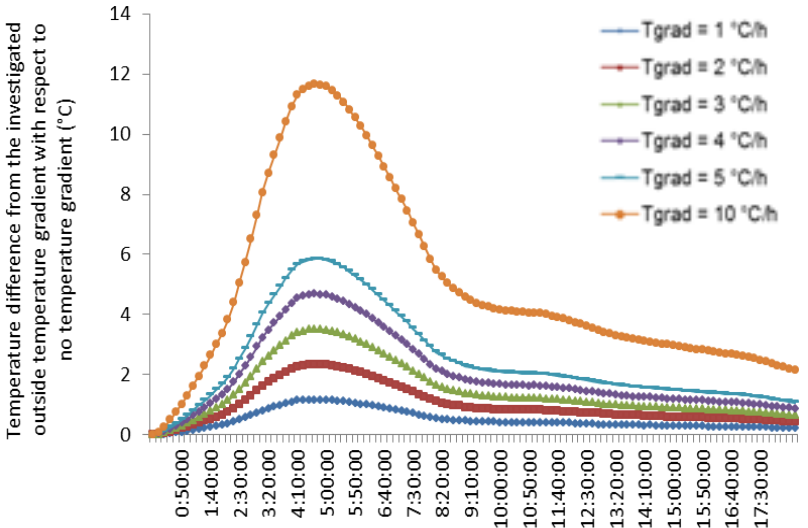

(b)

Fig. 7: External wall temperature difference due to an outside temperature gradient for (a) timber frame wall and (b) massive wall with inside insulation 


\section{SIMULATION GUIDELINES VS EXISTING GUIDELINES}

When the simulation results are compared to the existing guidelines, a number of observations can be made. First, looking at the solar irradiation, it can be noticed that the guidelines resulting from the simulations are very similar to the existing guidelines which have been established in Western Europe [3, 4]. Comparing these guidelines to the existing American guidelines, the ambiguity of the term "heavy thermal mass" can be noticed [2,5]. The waiting time of 8 hours lies more in the range of the partly filled and fully filled cavity wall, which is in this paper categorized as "medium" thermal mass (figure 2).

When the existing guidelines concerning wind velocity are compared to the simulation results, some observations can also be made. Figure 8 shows the temperature profiles for the combination of different wind velocities with an overcast sky and without solar irradiation for the timber frame wall. It is remarkable that even with strong and long lasting wind velocities up to $7 \mathrm{~m} / \mathrm{s}$ qualitative thermographic measurements are still possible. This is similar to the value of $6,7 \mathrm{~m} / \mathrm{s}$ which is found in the existing guidelines [2, 10] as a maximum tolerated wind velocity for qualitative measurements. If quantitative measurements are desired, Figure 8 shows that the wind velocity should be less than 2 $\mathrm{m} / \mathrm{s}$ (preferably $1 \mathrm{~m} / \mathrm{s}$ ). In the existing guidelines a similar recommendation is found. Because of the low thermal mass, timber frame wall constructions are more sensitive to these temperature modulating phenomena. Walls with a high thermal mass on the outside, e.g. the massive wall with inside insulation, are less sensitive to short lasting winds. In contrast with the timber frame wall a longer waiting time is recommended once the threshold value $\left(0,5^{\circ} \mathrm{C}\right.$ or $\left.2^{\circ} \mathrm{C}\right)$ has been exceeded before reliable thermographic measurements can be performed.

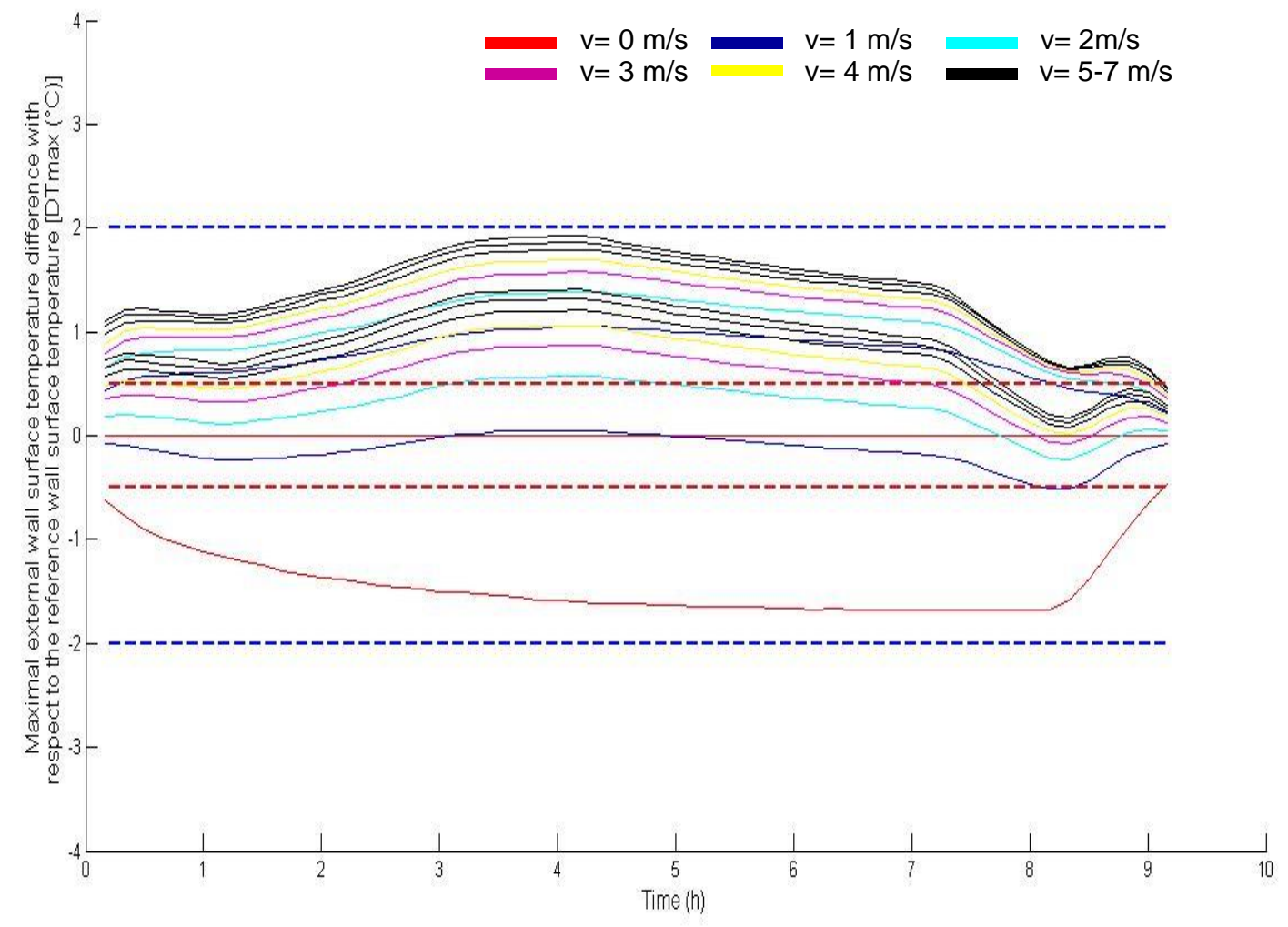

Fig. 8: Influence of the wind velocity on the outside wall surface temperature

Another environmental parameter that is discussed in the standards and in the scientific literature is the sky radiation. As mentioned before, the simulations show that an overcast sky is preferred for performing qualitative measurements and is essential when performing quantitative measurements. Except for its influence on the reflective temperature, the sky radiation also cools down the wall surface, as can be seen in Figure 9. Figure 9 shows that a clear sky directly results in a cooling effect that is larger than the threshold value. In combination with solar irradiation, a clear sky on the other hand, will shorten the waiting time, because in this case it partly compensates the warming up of the surface caused by the sun. 


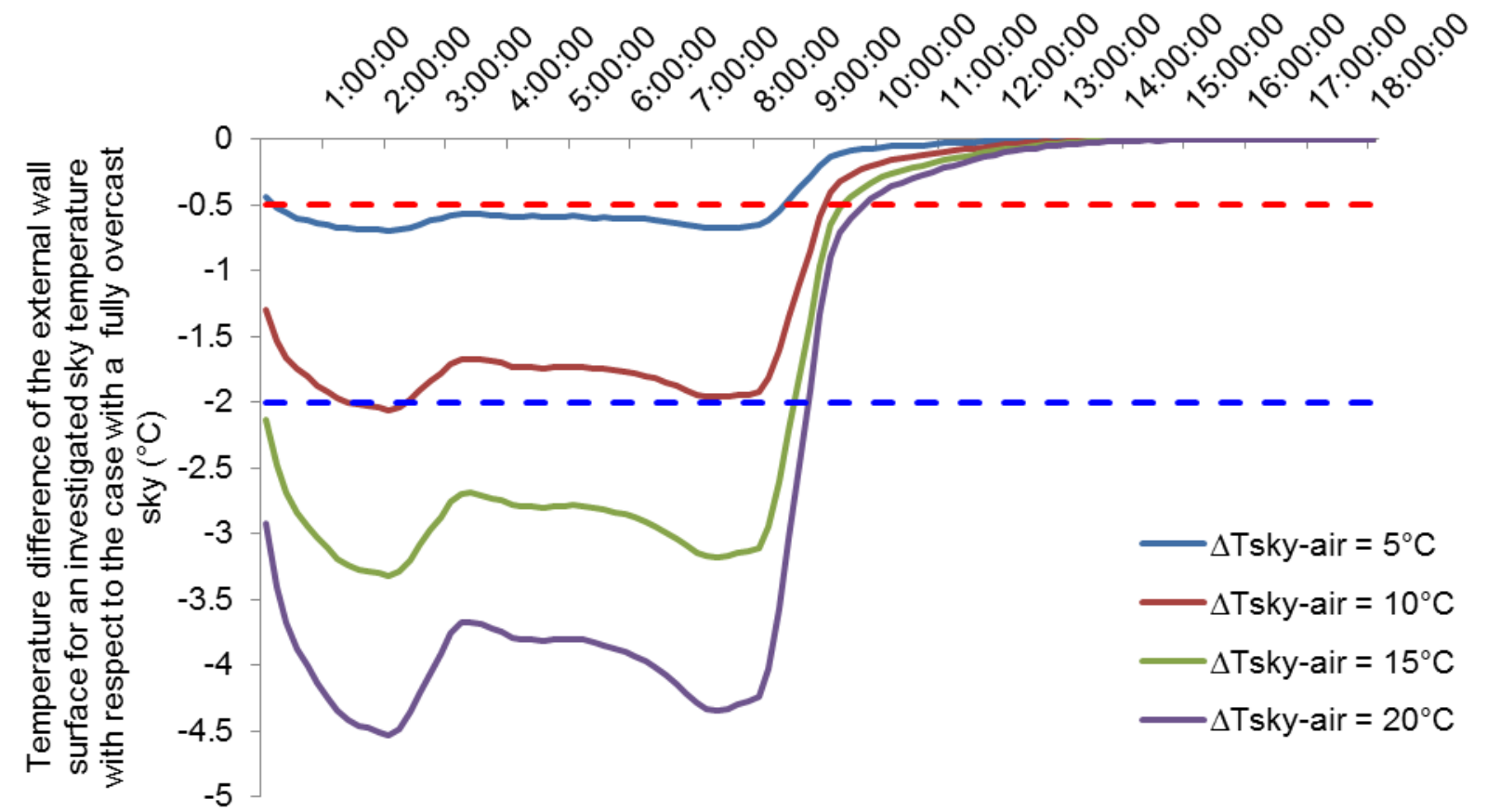

Fig. 9: Influence of the sky radiation on the outside wall surface temperature

Finally, the simulations have shown that the influence of the temperature gradient outside is very similar to what is found in literature. In table 5 the mean temperature change rates for the three categories of wall types are depicted. A slightly larger temperature change rate can be found for the wall types with medium and heavy thermal mass. This is caused by the slightly different thermal masses that have been used in these simulations [3, 4].

Table 5: Surface temperature gradient $\left(\Delta \mathbf{T}_{\mathrm{s}, \mathrm{grad}}\right)$ due to an outside temperature gradient $\left(\Delta \mathbf{T}_{\mathrm{e}, \mathrm{grad}}\right)$

\begin{tabular}{|c|c|c|c|}
\hline Construction type & Light & Medium & Heavy \\
\hline Temperature gradient & $\Delta \mathrm{T}_{\mathrm{s}, \text { grad }}=0,5^{*} \Delta \mathrm{T}_{\mathrm{e}, \mathrm{grad}}$ & $\Delta \mathrm{T}_{\mathrm{s}, \text { grad }}=0,45^{*} \Delta \mathrm{T}_{\mathrm{e}, \mathrm{grad}}$ & $\Delta \mathrm{T}_{\mathrm{s}, \text { grad }}=0,25^{*} \Delta \mathrm{T}_{\mathrm{e}, \mathrm{grad}}$ \\
\hline
\end{tabular}

\section{CONCLUSIONS AND FUTURE WORK}

Based on the simulation results, it could be observed that it is very hard to obtain the ideal conditions for quantitative thermographic measurements. Even for qualitative measurements stringent ambient conditions are necessary. An overcast sky and no solar irradiation, for example, are the minimum requirements to remain within the 2 ${ }^{\circ} \mathrm{C}$ threshold. When on top of that, the inaccuracies relating to the measurement of emissivity and reflectivity of the wall surface are considered, it is clear that quantitative measurements require additional research.

It should be noted that the values of solar irradiation, wind and sky radiation that were used in these simulations were rather theoretical, and led to a specific waiting time depending on the combination of phenomena. A survey that was conducted amongst a number of thermographers has shown that some of them already used a wind velocity meter for determining whether thermographic evaluation was reliable. However, For the solar irradiation for example, this results in a specific waiting time before executing a thermographic measurement depending on a precise value (e.g. $11400 \mathrm{~kJ} / \mathrm{m}^{2}$ ) of the solar energy absorbed by the wall. In practice, the absorbed solar irradiation is seldom measured which renders the translation to practical guidelines rather difficult. In the existing guidelines, therefore, only a distinction is made between sun or no sun. In theory this can for example be solved by using a pyranometer, but for the small thermograph company this could be a large investment.

In this paper the authors tried to make some differentiation between qualitative and quantitative thermographic purposes. In further research this could be further refined in specific guidelines for evaluation of insulation defects or guidelines for airtightness investigations, for instance in combination with a pressurization test.

\section{ACKNOWLEDGEMENTS}

The results presented in this paper were obtained within the framework of the research project IWT-TETRA 130210 funded by the Flemish Institute for the Promotion and Innovation by Science and Technology in Flanders. Their 
financial support is gratefully acknowledged. The authors would also like to thank P. Standaert for his support in modelling.

\section{REFERENCES}

[1] BPIE (2011). Europe's buildings under the microscope. A country-by-country review of the energy performance of buildings. Buildings performance institute Europe (BPIE), Brussels

[2] ASTM C1060 - 11a, "Standard practice for thermographic inspection of insulation installations in envelope cavities of frame buildings". ASTM American society for testing and materials, 2011.

[3] Tanner C., Lehmann B., Thomas F., Ghazi Wakili K., "Vorschlag zur standardisierten darstellung von wärmebildern mit QualiThermo". Bauphysic 33, Heft 6, 2011.

[4] Lehmann B., Ghazi wakili K., "Effects of individual climatic parameters on the infrared thermography of buildings". Applied Energy 110, 29-43, 2013.

[5] Colantonio A., McIntosh G., "The differences between large buildings and residential infrared thermographic inspection is like night and day". 11th Canadian Conference on Building Science and Technology, P. 13, Alberta, 2007

[6] NBN EN 13187, "Thermal performance of buildings - Qualitative detection of thermal irregularities in building envelopes - Infrared method". BIN, Brussels, Belgium, 1999.

[7] BS EN 13187: 1999, "Thermal performance of buildings - Qualitative detection of thermal irregularities in building envelopes - Infrared method". BSI, London, 1999.

[8] Dall'O' G., Sarto L., Panza A., "Infrared screening of residential buildings for energy audit purposes: results of a field test". Energies 6, 3859-3878, 2013.

[9] Balaras C. A., Argiriou A.A., "Infrared thermography for building diagnostics". Energy and Buildings 34, 171183, 2002.

[10] Eads L., Epperly R., Snell J., "Thermography: Practical guide”. ASHRAE Journal's, March 2010, 51-55, 2000.

[11] Fokaides P. A., Kalogirou S. A., "Application of infrared thermography for the determination of the overall heat transfer coefficient (U-Value) in building envelopes". Applied Energy 88, 4358-4365, 2011.

[12] Taylor T., Counsell J., Gill S., "Energy efficiency is more than skin deep: Improving construction quality control in new-build housing using thermography". Energy and Buildings, 66, 222-231, 2013.

[13] Albatici R., Tonelli A., "Infrared thermovision technique for the assessment of thermal transmittance value of opaque building elements on site". Energy and Buildings 42, 2177-2183, 2010.

[14] Behaneck M., "Bauthermografie-Praxis: Tipps \& Tricks für Einsteiger". Gebäude energie berater 2, 44-49, 2011.

[15] VATh, "Bauthermografie: zur Planung, Durchführung und Dokumentation infrarotthermografischer Messungen an Bauwerken oder Bauteilen von Gebäuden". Bundesverband für Angewandte thermografie e.V., p. 15, 2011.

[16] Dall'O' G., "Infrared audit". Green energy audit of buildings, 111-125, Springer-Verlag London, 2013.

[17] TheCH, "Standard de qualité bâtiment". Association Suisse de thermographie (theCH), Neuhausen, Switzerland, 2010.

[18] Barreira E., de Freitas S. S., de Freitas V. P., Delgado J. M. P. Q., "Infrared thermography application in building diagnosis: A proposal for test procedures”. Infrared Thermography Application in Building Diagnosis, Springer-Verlag Berlin Heidelberg, 91-117, 2013.

[19] Charlier L., "Utilisation de la thermographie infrarouge pour la determination des déperditions thermiques d'un bâtiment”. Université de Liège, 2007.

[20] RESNET, "Interim guidelines for thermographic inspections of buildings". RESNET Residential energy services network, 2012.

[21] Pearson C., "Thermal Imaging of Building Fabric". BSRIA Guide39, p. 30, 2011.

[22] ASTM E1862 - 97, "Standard Test Method for Measuring and Compensating for Reflected Temperature Using Infrared Imaging Radiometers". ASTM American society for testing and materials, 2002.

[23] Asdrubali F., Baldinelli G., Bianchi F., "A quantitative methodology to evaluate thermal bridges in buildings". Applied Energy 35, $365-373,2012$.

[24] Bérubé Dufour M, Derome D., Zmeureanu R., "Analysis of thermograms for the estimation of dimensions of cracks in building envelope". Infrared Physics \& Technology 52, 70-78, 2009.

[25] PHYSIBEL, "VOLTRA - 3-dimensional dynamic simulation tool using the finite element method". Version 7.0, Physibel Software, Maldegem, Belgium; 2008.

[26] Remund J., Kunz S., " Test Reference Year Weather Data File of Ukkel (Belgium)”. METEOTEST, Bern, Switzerland.

[27] Willockx A., "Using the inverse heat conduction problem and thermography for the determination of local heat transfer coefficients and fin effectiveness for longitudinal fins". Doctoral paper, University of Ghent, p. 283, 2010. 